\title{
Notas sobre a visita de Carl Rogers ao Brasil: uma revolução silenciosa
}

\section{Notes on the visit of Carl Rogers to Brazil: a silent revolution \\ Notas sobre la visita de Carl Rogers a Brasil: una revolución silenciosa}

\author{
Ellen Araújo Lima Feitosa* \\ Universidade Federal da Bahia - UFBA, Vitória da Conquista, Bahia, Brasil
}

\author{
Paulo Coelho Castelo Branco** \\ Universidade Federal da Bahia - UFBA, Vitória da Conquista, Bahia, Brasil
}

Emanuel Meireles Vieira***

Universidade Federal do Pará - UFPA, Belém, Pará, Brasil

\begin{abstract}
RESUMO
Neste artigo, objetivamos analisar a vinda de Carl Rogers ao Brasil com base em três momentos: antes, durante e depois de sua primeira visita, em 1977. Inicialmente, identificamos a ideia rogeriana de política como central ao seu pensamento. Depois, analisamos: as correspondências que antecederam e organizaram tal vinda; a proposta de intervenção psicológica-ideológica que Rogers expressou em uma entrevista à Revista Veja; os efeitos dessa visita, segundo os relatos de Rogers publicados, posteriormente, em suas obras. As ideias democráticas de Rogers serviram de justificativa para a sua vinda em plena Ditadura Militar. Contudo, elas foram assimiladas com ressalvas por alguns psicólogos brasileiros, conforme aportes críticos norteados, sobretudo, pelos ideais marxistas e freirianos. Desse movimento, emergiram outras perspectivas de ACP e algumas influências no desenvolvimento da Psicologia Comunitária. Concluímos que Rogers inspirou diversas Psicologias locais imersas em uma série de conjeturas críticas sobre o lugar de ideias políticas, passiveis de serem cooptadas e reconfiguradas, acriticamente, a partir de uma ótica capitalista voltada para a redemocratização do Brasil.
\end{abstract}

Palavras-chave: Carl Rogers, História da Psicologia, Política.

\begin{abstract}
We aimed to analyze the coming of Carl Rogers to Brazil based on three stages: before, during and after his first visit in 1977. Initially, we noticed that the Rogerian idea of politics as the center of his political thought. Then we analyzed the letters that preceded and organized this coming; the proposal of a psychological-ideological intervention that Rogers stated in an interview with Veja magazine; the effects of this visit, according to Rogers reports published later in his works. Democratic ideas of Rogers served as justification for his appearing during Brazilian military dictatorship. However, some Brazilian psychologists assimilated them with caveats with critical
\end{abstract}


contributions based, especially, in Marxist and Freirean ideals. From this movement, emerged other perspectives of PCA and some influences in the development of Community Psychology. We conclude that Rogers inspired several local Psychologies immersed in many critical assumptions about the place of political ideas, which can be co-opted and reconfigured, uncritically, from a capitalist perspective toward the democratization of Brazil.

Keywords: Carl Rogers, History of Psychology, Politics.

\begin{abstract}
RESUMEN
Este artigo objetiva evaluar la venida de Carl Rogers en Brasil basado en tres etapas: antes, durante y después de su primera visita en 1977. De inicio, identificamos la idea de política como elemento central del pensamiento de Rogers. Luego analizamos: las correspondencias que anteceden e organizan su venida; la propuesta de intervención psicológica ideológico que Rogers declaró en una entrevista a la Revista Veja; los efectos de esta visita, de acuerdo con informes de Rogers publicados más tarde en sus obras. Los ideales democráticos de Rogers sirvieron como justificación de su visita en plena dictadura militar. Sin embargo, fueron asimilados con reservas por algunos psicólogos brasileños según perspectivas críticas que se guían especialmente por los ideales marxistas y de Paulo Freire. Desde este movimiento, emergieron otras perspectivas del ECP y algunas influencias en el desarrollo de la Psicología Comunitaria. Llegamos a la conclusión de que Rogers inspiró varios psicólogos locales inmersas en una serie de conjeturas críticas al lugar de ideas políticas, que pueden ser cooptadas y reconfiguradas, sin crítica, desde el punto de vista capitalista hacia la redemocratización de Brasil.
\end{abstract}

Palabras clave: Carl Rogers, Historia de la Psicología, Política.

\title{
I ntrodução
}

Neste artigo, de cunho ensaístico e reflexivo, objetivamos analisar a vinda de Carl Rogers ao Brasil, com base em três momentos históricos situados antes, durante e depois de sua primeira visita ao Brasil, em 1977, e os seus desdobramentos na Abordagem Centrada na Pessoa (ACP) nacional e na Psicologia Comunitária. Naquele ano, o país estava imerso em uma conjuntura política de regime ditatorial militar, que curiosamente recebeu o expoente humanista, a despeito das ressalvas do mencionado regime às ideias políticas rogerianas e em razão das estratégias de alguns psicólogos brasileiros que mobilizaram tal evento.

O interesse de investigar esse tema ocorre mediante uma visada histórica que busca entender os efeitos do encontro de Rogers com o cenário brasileiro, seja na experiência desse autor, seja nos desenvolvimentos locais de uma Psicologia brasileira. Propomos, pois, um enfoque histórico contextual (Brock, 2014) que perfilha um entendimento sobre esse ponto na extensa carreira de Rogers. Desta, salientamos que muito se houve, mas, ainda, há alguns pontos que pouco se ouvem. Ressaltamos, também, que essa visada sobre Rogers se baseia no pressuposto de que a compreensão histórica da 
visita desse autor ao Brasil está repleta de tramas sociais, políticas e científicas.

Com efeito, procedemos da seguinte lógica expositiva para tratar do objetivo proposto. Inicialmente, apresentamos a ideia rogeriana de política. Em seguida, analisamos Rogers no Brasil em três momentos: no primeiro, situamos os aspectos contextuais que antecederam a vinda, com base nas cartas trocadas entre o expoente humanista e Eduardo Bandeira, estudante de psicologia e empresário que organizou o evento; no segundo, ponderamos a proposta de intervenção psicológica-ideológica que Rogers apresentou em uma entrevista concedida a Revista Veja, em 1977; no terceiro, demonstramos os efeitos da vinda de Rogers ao Brasil, segundo os relatos que $o$ autor publicou em suas obras posteriores ao evento. Argumentamos, finalmente, que a visita de Rogers ao Brasil, ensejou uma mobilização de ideias políticas críticas ao capitalismo estadunidense que, posteriormente, possibilitou a assunção de algumas correntes de abordagem centrada na pessoa (ACP) pósRogers, nos anos de 1980, notoriamente influenciadas pelos aportes do Marxismo, da Pedagogia de Paulo Freire, da Teoria Crítica, da Fenomenologia e do Existencialismo. Além de influenciar, também, uma proposta de Psicologia Comunitária.

\section{I deia de política no pensamento de Carl Rogers}

Carl Rogers, depois de se aposentar das atividades de docência e pesquisa na Universidade de Winsconsin, em 1963, mudou-se para La Jolla - Califórnia, onde passou a estudar paradigmas de ciência alternativos aos modelos comportamentais da Psicologia e a exercer práticas que objetivavam expandir alguns elementos de sua reconhecida abordagem clínica, a Terapia Centrada no Cliente, em outros campos relacionais, como o microcosmo grupal, matrimonial e educacional (Kirschenbaum, 2007). Em virtude desses trabalhos, Rogers entendeu que a alcunha de Terapia Centrada no Cliente não representava mais o seu pensamento, então preocupado com as dimensões relacionais além do ambiente clínico. Por isso, Rogers estabeleceu, em 1977, a nomenclatura de Abordagem Centrada na Pessoa (ACP). Esta continha alguns elementos anteriores da clínica, sobretudo as atitudes relacionais de congruência, consideração incondicional e compreensão empática, contudo não mais articuladas com outras atitudes e pressupostos que objetivavam mudar a personalidade em um processo psicoterapêutico (Rogers, 1977).

Outras ideias, destarte, articulam-se com o arcabouço teórico de Rogers. Essas ideias, segundo ponderamos, são políticas e evocam outro modo de pensar intervenções relacionais sobre o(s) outro(s). Na obra Sobre o poder pessoal (1977) encontramos pela primeira vez 
na carreira de Rogers a apresentação escrita do termo ACP. Curiosamente a primeira parte que compõe o mencionado livro recebeu o título de Uma revolução silenciosa: o impacto da abordagem centrada na pessoa, composta por capítulos que aludem à implicação dessa abordagem nas profissões de ajuda, na família, no casamento, na educação, na administração, no diálogo com a Pedagogia do Oprimido de Paulo Freire e nas tensões interculturais. Nessa parte, ressaltamos que a noção de política se demonstra presente em tais implicações.

Rogers (2001) afirma que a essência da ACP é o argumento de que todo homem é digno de confiança, reconhecendo que essa é uma premissa relacional arriscada, pois recai em uma perspectiva de discussão sobre questões políticas de controle e poder sobre o outro. Para o autor, a prática e o ensino das atitudes centradas na pessoa conduzem a um ideal político de relação e crescimento humano. Ele reconhece, inicialmente, que a palavra política está relacionada aos métodos e táticas, intencionais ou não, de poder e controle empreendidos pelo Estado ou Governo. De um modo geral, tal acepção refere-se a um lugar de poder e tomada de decisões que afetam os sentimentos e os comportamentos de um indivíduo ou de vários grupos. Essa perspectiva envolve um processo de adquirir o poder, compartilhá-lo ou abandoná-lo em favor da tomada de certas decisões que afetam os outros.

Com base em sua experiência clínica relacional, Rogers (2001) entende que existe um caráter político na sua forma de abordar as pessoas e, por conseguinte, nos pressupostos da ACP. Interessado nas condições que possibilitam mudanças relacionais, Rogers entende que o foco do crescimento deve sempre partir da base experiencial da pessoa. O objetivo de sua abordagem não é tratar o problema da pessoa, mas auxiliá-la em seu crescimento, ou seja, ampliar a sua experiência, para que ela possa resolver os seus problemas pessoais e sociais de forma mais integrada. É função da ACP e de todas as suas manifestações terapêuticas individuais e grupais libertar a pessoa para que ela possa crescer e superar os seus obstáculos para se autorrealizar.

Em outros termos, mais teóricos, Rogers (1977) entende a experiência como tudo aquilo que perpassa o organismo e está potencialmente disponível para ser simbolizado pela consciência. Defronte a tensão oriunda da discrepância entre as demandas do organismo e as do ambiente, a consciência emerge como uma função que objetiva reconhecer a tensão que a gera, simbolizar, ou seja, dar sentido ao que the acontece no presente momento e possibilitar ações direcionadas à resolução deste conflito (Rogers, 2001).

Nesse movimento, é possível observar a manifestação da tendência à realização, movimento vital presente em todos os seres vivos que implica uma direção à concretização das potencialidades que cada 
pessoa tem para o crescimento e a integração de suas experiências. Esse é um substrato para a motivação humana para ir além do equilíbrio com o ambiente e se responsabilizar pelo empreendimento decisões e ações que visam à modificação de si e/ou do ambiente. Por isso, Rogers (2001) entende que a ACP parte de uma base que reconhece a experiência de cada pessoa como o ponto de partida para qualquer transformação individual, interpessoal e social. Nessa afirmação, o autor reconhece a existência de uma ideia política na noção de autorrealização, pois esta possibilita a assunção de um plano interventivo, no caso a ACP, que tenta possibilitar que a pessoa acesse a sua experiência, reconheça o que a perpassa, simbolize-a conforme aquilo que lhe faz sentido, tome decisões e empreenda ações aptas para um direcionamento harmonioso de relações sociais que considere as experiências alheias como fontes válidas de conhecimento. Para gerar essa teleologia, em suma, Rogers (2001) argumenta que a política da ACP

(...) baseia-se na premissa de que o ser humano é basicamente um organismo digno de confiança, capaz de avaliar a situação externa e interna, compreendendo a si mesmo no seu contexto, fazendo escolhas construtivas quanto aos próximos passos da vida e agindo a partir dessas escolhas. Uma pessoa facilitadora pode ajudar na libertação dessas capacidades (...). Quando essa abordagem é dirigida a um indivíduo ou a um grupo, (...) as escolhas feitas, as direções seguidas, as ações empreendidas são pessoalmente cada vez mais construtivas e tendem para uma harmonia social mais realística com os outros (p. 17).

O poder não está naquele que facilita o processo, no caso o psicólogo, mas em quem o vivencia, no caso o(s) cliente(s). Por mais que o facilitador seja investido de poder, no decorrer da relação, ele abdica desse lugar para possibilitar um empoderamento pessoal/social do outro. É nessa acepção que Rogers entende, portanto, que existe uma ideia de política em sua abordagem e que esta tem um efeito de fermento de mudança social em diversos campos relacionais. Assim, a ACP desenvolve uma revolução silenciosa que preconiza novas formas de se relacionar socialmente (Rogers, 2001).

Embora parta de uma discussão individual no campo da psicoterapia, Rogers avança para uma tentativa de compreender em que medida indivíduo e sociedade se relacionam e se influenciam. Não é à toa, por exemplo, que Rogers (2001) escolhe a obra de Paulo Freire para tentar estabelecer um parâmetro de comparação política com o seu trabalho. Podemos entender que Rogers partiu de uma preocupação com a forma de estabelecimento de uma relação terapêutica que funcione para uma série de reflexões sobre que espaço há para a 
participação de cada um na construção coletiva. Isso fica evidente na seguinte passagem:

Violência cega contra as pessoas não pode ocorrer e não ocorre em uma cultura em que cada indivíduo sente-se como parte de um processo em andamento e com finalidade. O indivíduo precisa estar completamente alienado da corrente principal da sociedade para que a violência impessoal se torne possível. $\mathrm{Na}$ China, uma cultura muito diferente da nossa, a violência impessoal ao acaso que é comum em nossas cidades é, pelo que se sabe, virtualmente desconhecida. Isto não se deve ao fato de os chineses serem incapazes de violência. Lá tem havido fanáticas tentativas para matar proprietários de terras ou adversários da Revolução Cultural e outras pessoas desse tipo. Mas, na vida diária, os chineses estão organizados em grupos locais com uma boa dose de autogoverno. Além disso, eles se sentem, de modo surpreendente, interessados na reconstrução de seu país (Rogers, 2001, p. 290).

A citação evidencia um Rogers preocupado em entender de que modo o valor de cada um atua na construção de um senso de coletividade. Ao indivíduo, o coletivo não pode se apresentar apenas como uma série de obrigações morais, ao passo que ao coletivo cabe reconhecer - valor da singularidade de cada pessoa. Essa perspectiva é atravessada por um entendimento político presente nos grupos do que se chamavam nos EUA daquele tempo, a "nova esquerda". Nova, porque se fundamentava na "(...) crença americana tradicional na democracia, embora reivindicada para 'o povo', e em direção a uma maior igualdade econômica também" (Farber \& Bailey, 2001, p. 31), e não a um entendimento marxista de luta de classes ou algo do gênero. Esse movimento, protagonizado por jovens universitários que sonhavam com uma nova sociedade para além daquela do consumo que surgiu no pós-guerra, pautava-se pela ideia de que uma sociedade cujos alicerces deveriam ser o amor, a fraternidade e a paz.

\section{Momentos da visita de Carl Rogers ao Brasil}

Com a proposta de fazer uma apresentação didática sobre a visita de Carl Rogers ao Brasil, dividimos esse evento em três momentos reflexivos para, posteriormente, ponderarmos alguns efeitos do encontro desse autor com o cenário nacional. Dessa forma, o primeiro momento foi denominado de Carl Rogers antes da visita ao Brasil, o segundo intitulado Carl Rogers no Brasil e o terceiro chamado Carl Rogers e o seu relato de experiência sobre o Brasil. Apresentamos, em seguida, cada um deles. 
Carl Rogers antes da visita ao Brasil

Em meados da década de 1970, Eduardo Bandeira, então estudante de Psicologia e empresário estabelecido em São Paulo, empenhou-se em mediar a vinda de Carl Rogers para o Brasil, com a finalidade de promover cursos e workshops de facilitação grupal. Bandeira visitou Rogers no Centro de Estudos da Pessoa, em La J olla - Califórnia e, ao retornar ao Brasil, disseminou o material obtido naquele Centro (Gomes, Holanda \& Gauer, 2004). Percebendo o interesse de vários psicólogos brasileiros na ACP, em plena Ditadura Militar, Bandeira começou a articular a vinda de Rogers ao Brasil buscando o apoio de outros psicólogos, como Rachel Lea Rosenberg, Lúcio Flávio Campos, Maria Auxiliadora Moura entre outros. Assim, em 1976, Bandeira começou a trocar correspondências com Rogers.

Nos EUA, Rogers contava com uma equipe de facilitadores, que costumava viajar com ele pelo mundo em diversos eventos demonstrativos da ACP. A equipe era composta por John Wood, Maureen O'Hara, Jack Bowen e a brasileira Maria Constança VillasBôas Bowen (esposa de Jack). Em uma das primeiras cartas trocadas com Bandeira, Rogers expressou interesse e receio pelo convite. Nas palavras do expoente humanista,

A noção de impactar todo o país me empolga, e me parece que seus planos são tais que isso pode muito bem acontecer. Eu gostaria, particularmente, de que tudo que nós fizermos seja no sentido de fortalecer as raízes dos movimentos em direção à democracia (Bandeira, 2012, p. 40).

Percebemos que Rogers estava interessado na situação política do Brasil. Nesse relato, é notória a vontade dele de contribuir com o fortalecimento da democracia brasileira. Podemos notar que as ideias políticas da ACP estão retratadas nesse sucinto fragmento de carta. Rogers compreendia que sua ida ao Brasil poderia impactar o país imerso em uma Ditadura política, em que ele enquanto facilitador poderia influenciar outros psicólogos centrados na pessoa a contribuir com o processo de redemocratização nacional.

A despeito disso, Rogers apresentou, também, receio em vir para o Brasil. Com 75 anos de idade e algumas debilitações físicas, ele se inquietou em relação ao tempo de viagem e a possibilidade de seu trabalho não ser assimilado ante uma conjuntura política de censura e desconfiança em relação às práticas humanistas, tradicionalmente, associadas à contracultura (Grogran, 2012). Para exemplificar essa situação, em 1975, ocorreu o assassinato de Vladimir Herzog, jornalista militante do Partido Comunista Brasileiro e preso político na época. Em decorrência disso, em São Paulo, intensificou-se a censura 
no teatro, na mídia, além da repressão política às ideias consideradas comunistas ou contraculturais (Dantas, 2014). Esse contexto de censura gerou receios em Bandeira e Rogers em relação a um evento de ACP no Brasil. Tais receios e inquietações, contudo, não foram o suficiente para Rogers recusar o convite, pois ele e a sua equipe estavam ansiosos para a divulgação do trabalho e das ideias centradas na pessoa de liberdade, consciência e democracia.

Carl Rogers no Brasil

A primeira visita de Carl Rogers ao Brasil, em 1977, foi antecedida por um prelúdio de cinco dias de descanso e organização em Manaus, onde foram acordadas as estratégias sobre o formato dos eventos que se sucederiam. Em Recife, Rogers e sua equipe realizaram um evento para uma plateia estimada em oitocentas pessoas no ginásio do Sport Club do Recife. Depois, em São Paulo, o evento aconteceu no Centro de Convenções no Anhembi, para uma plateia média de mil pessoas e, finalmente, houve um grande evento vivencial da ACP, intitulado I Encontro Centrado na Pessoa, na Aldeia de Arcozelo, em Paty dos Alferes, serra Fluminense. Esse encontro contou com a participação média de duzentas pessoas (Gomes et al., 2004; Bandeira, 2012).

Curioso notar que, nesse primeiro ano em que Rogers esteve no Brasil, havia, frequentemente, policiais acompanhando o desencadear dos eventos mencionados. Na ocasião da participação de Rogers e sua equipe na TV Cultura (1977), onde demonstravam um processo de facilitação grupal, Eduardo Bandeira foi convocado para depor sobre a natureza do evento no Departamento de Ordem Política e Social (DOPS). Não podendo evitar a convocatória, ele foi depor. Em suas palavras, que recordam o depoimento, Bandeira se sentiu,

Tranquilo, pois estava muito consciente de que nós fazíamos um trabalho para fortalecer a democracia, ou seja, a liberdade consciente, o oposto da esquerda radical totalitária que eles não admitiam. Eu via a ACP pelo viés democrático, longe de todo o totalitarismo, fosse de direita ou de esquerda. Essa era a proposta de Carl e também a nossa. Eu tinha convicção de que a grande preocupação do governo revolucionário militar era com os comunistas extremistas, que nessa altura estavam em luta armada com o governo, e como nós não éramos comunistas, não haveria problema algum em ir lá e conversar com o delegado. Como no final aconteceu (Bandeira, 2012, p. 82-83).

No relato de Bandeira é possível identificar o modo como aparecem as ideias políticas da ACP. Estas aludem a uma transformação política 
democrática de dentro para fora, ou seja, iniciada a partir da experiência de cada pessoa, para que ela possa multiplicar e desenvolver uma sociedade mais harmoniosa (Rogers, 2001). Não obstante isso, porém, existe a seguinte indagação: como as ideias políticas de Rogers puderam ser recepcionadas no Brasil em pleno regime militar?

Em 1977, apesar de existir ainda a ditadura, havia uma pressão social para a redemocratização do Brasil. Nesse sentido, as ideias políticas de Rogers eram uma alternativa às até então presentes na oposição da esquerda com ideais marxistas. Uma possível democracia com ideias oriundas dos EUA poderia ser uma alternativa viável naquele período histórico, visto que, apesar de os princípios serem focados na pessoa e em sua liberdade, essas questões podiam ser facilmente reconfiguradas a partir de interesses dos políticos da época. Uma concepção de política com base na experiência do indivíduo, conforme defendida pela ACP e por outros movimentos jovens dos anos 1960 e 1970, diferentemente do ideal comunista que visa ao social, antes dos interesses individuais, poderia ser cooptada pelo capitalismo a partir do plano de liberdade e da consideração dos interesses individuais, incitando uma ideia democrática individualista. Traçando um sucinto paralelo com relação à contracultura e às ideias democráticas da ACP, é possível dizer que, não por acaso, os jovens da contracultura, sem saber muito bem definir o que queriam, tinham clareza do modelo que não gostariam de adotar como filosofia de vida - o do consumo, o da guerra, o da política tradicional. Assim, entendiam que a mudança necessária em seu tempo era de consciência, e não de ideologia, de tal forma que “(...) a construção da boa sociedade não é uma tarefa primordialmente social, e sim psíquica" (Roszak, 1968/1972, p. 61). Da mesma forma, Rogers entendia que uma mudança de postura nas relações pessoais e na consciência do mundo poderia levar a uma transformação dos outros fatores envolvidos no campo social.

Essas inferências podem ser argumentadas a partir de uma entrevista de Rogers à Revista VEJA, no período em que ele esteve no Brasil. Criada em 1968, frequentemente, VEJA é acusada de ser um mecanismo de impressa que serviu para exaltar os interesses do regime político ditatorial e os interesses do capital estrangeiro (Dantas, 2014). Rogers (1961/1997) era bastante famoso naquela época, pois contava com centenas de artigos publicados e um livro, Tornar-se Pessoa (1961), considerado um best seller, traduzido para dezenas de línguas. Obviamente, essa fama e a repercussão da vinda de um ícone internacional da Psicologia às terras brasileiras renderam algumas páginas na Revista Veja. Na seção de entrevista com Rogers, publicada no número 441, no dia 16 de fevereiro de 1977, o entrevistador perguntou o que ele achava da psicologia acadêmica, obtendo a seguinte resposta: 
Nos Estados Unidos, a psicologia acadêmica poderia dar excelente aconselhamento e ajuda a governos ditatoriais. Acho que, se qualquer autoridade diz 'queremos que as pessoas sejam mudadas desta forma', a psicologia acadêmica sabe muito bem como mudar as pessoas, gradualmente, no sentido que se quiser. E vejo isso como um grande perigo. A psicologia humanista seria uma valiosa conselheira a uma forma de governo democrático, pois ela o ajudaria a ser cada vez mais democrático, a compreender as capacidades, os direitos e a habilidade do cidadão de ser responsável (Revista VEJA, 1977).

Nesse sentido, conforme já mencionamos, como uma representante da Psicologia Humanista, a ACP preconiza uma teleologia democrática, a qual o cidadão compreende suas experiências, direitos e é responsável pela sua situação pessoal/social. Rogers acreditava que a ideia política da ACP poderia ter interfaces importantes para a transição do período ditatorial para um processo de redemocratização do Brasil. Ainda nessa entrevista, Rogers explica sua noção de tendência à realização. Conforme o autor,

O ser humano, como todos os organismos, tende a crescer e a se atualizar. É claro que todos os fatores sociais, econômicos e familiares podem interromper esse crescimento, mas a tendência fundamental é em direção ao crescimento, ao seu próprio preenchimento ou satisfação. (...) A pedra fundamental da psicologia humanista pelo menos como eu vejo, é, portanto, essa crença de que o ser humano tem um organismo positivo e construtivo (Revista VEJA, 1977).

Apesar da individualidade presente na ACP e de algumas ideias políticas poderem ser utilizadas para a manutenção do capitalismo, 0 entrevistador questiona como seria para Rogers um governo com uma visão humanista. Ele responde:

Para mim, isso é um sonho, mas seria bom esquematizar uma utopia com um governo humanista. Quanto mais um governo acredita num ponto de vista humanista possibilidades existirão de promover um clima no qual os cidadãos possam crescer e trabalhar junto mais harmoniosamente, e no qual haverá mais compreensão, ou respostas, as suas necessidades. Mas não vejo nenhuma possibilidade do que eu chamaria de um governo humanista (Revista VEJ A, 1977).

Nesse relato, é possível identificar que essa sociedade seria justa e igualitária, de modo que as pessoas viveriam de forma harmoniosa e 
existiria compreensão ou respostas às suas necessidades. Dessa forma, apesar de algumas ideias políticas rogerianas poderem ser utilizadas no sistema democrático, uma sociedade com a visão humanista não seria exatamente o que já existia, pois seria uma outra opção democrática à Ditadura Militar.

Após a primeira visita de Rogers ao Brasil, em 1977, ele retornou em 1978 e 1985, para realizar eventos semelhantes com a sua equipe. Sem dúvida, a ênfase vivencial da ACP foi algo que marcou o público brasileiro, ocasionando a assunção de uma ACP brasileira influenciada pelos aportes rogerianos, dotada de expoentes e com desenvolvimentos teóricos e práticos nacionais.

Rogers publicou três livros no Brasil (Rogers \& Rosenberg, 1977; Rogers, Wood, O'Hara \& Fonseca, 1983; Rogers, Santos \& Bowen, 1987). O primeiro, intitulado, A pessoa como centro (1977), em parceria com Rachel Lea Rosenberg, continha alguns textos de Rogers que, posteriormente, foram publicados em 1980, nos EUA, no livro A way of Being (Um jeito de ser, 1983). Rogers, ainda, publicou os seguintes livros, somente lançados no Brasil: Em busca de vida: da terapia centrada no cliente à abordagem centrada na pessoa (1983), com John Wood, Maureen O'Hara e o alagoano Afonso Fonseca; e Quando fala o coração: a essência da psicoterapia centrada na pessoa (1987), com os psicólogos brasileiros Maria Villas-Bôas Bowen e Antônio Monteiro dos Santos - este ainda incluiu uma entrevista que fez a Rogers na obra, publicada em 2004, intitulada Momentos Milagrosos: a natureza da mente nos relacionamentos e na psicoterapia (Santos, 2004).

Na última visita de Rogers ao Brasil, em 1985, em Brasília, merece destaque que ele deixou claro, em uma fala, seu receio em relação aos rogerianismos e que o próprio não se considerava um rogeriano, afirmando que o caráter da ACP é de abertura a inovações e outras possibilidades de desenvolvimento teórico e prático. $O$ mais importante, para Rogers, era que cada psicólogo encontrasse e desenvolvesse o seu próprio jeito de ser centrado na pessoa (Tassinari \& Portela, 2002).

\section{Carl Rogers e o seu relato de experiência sobre o Brasil}

Em algumas publicações posteriores a primeira visita de Carl Rogers ao Brasil, em 1977, é possível encontrarmos alguns fragmentos que relatam o impacto que a sua visita exerceu em sua experiência. No livro Um jeito de ser (1980/1983), no capítulo Crescer envelhecendo ou envelhecer crescendo?, Rogers abordou sua perspectiva sobre o tema da velhice, enfatizando-a como um processo de abertura a novas experiências. Conquanto o referido capítulo aborde um tema aparentemente deslocado de nossa proposta ensaística, nesse opúsculo Rogers expressa, como um exemplo de ampliação de 
experiência em sua velhice, a questão de se deslocar em uma viagem de aproximadamente quinze horas para o Brasil para promover a ACP em um território marcado pelo regime ditatorial militar. Rogers (1980/1983) afirma, inclusive, que talvez a viagem, realizada em 1977, tenha sido o que ele fez de mais arriscado em seus 75 anos de idade.

Rogers (1980/1983) relata que alguns de seus amigos achavam que seria uma viagem muito longa e cansativa - ele mesmo tinha esse receio. Outras pessoas duvidavam que ele pudesse influenciar um país tão grande quanto o Brasil, supondo-lhe uma arrogância. Ele destaca, entretanto, que a proposta de visitar o Brasil Ihe era muito atraente, além da ideia de treinar facilitadores brasileiros para atuações grupais, enfatizando a concepção de política da ACP, em que o foco é o indivíduo e no que este é capaz de multiplicar. Rogers preferiu não focar somente conferências sobre a ACP, encurtando as palestras para facilitar grupos. A maior dificuldade relatada por Rogers (1980/1983) aconteceu mediante o desafio de empregar essa proposta para os públicos grandes que participaram dos seus eventos em Recife, São Paulo e Rio de Janeiro. Segundo o autor,

Depois da primeira noite em São Paulo, em seguida a uma sessão extremamente caótica, eu estava nitidamente consciente de que só tínhamos mais seis horas com o grupo. Lembro-me de que me recusei a falar com quem quer que fosse sobre a reunião. Eu estava tremendamente confuso. Ou bem havia ajudado a desencadear um experimento incrivelmente estúpido e fadado ao fracasso, ou bem havia ajudado a criar um novo modo de permitir que oitocentas pessoas sentissem suas potencialidades e participassem na formação de sua própria experiência de aprendizagem. (...) Até então, jamais fizera uma viagem tão longa que tivesse sido tão proveitosa. Aprendi muito, e não há dúvida de que tornamos possível a criação de um clima facilitador de todo tipo de coisas criativas - nos níveis pessoal, interpessoal e grupal (p. 20-21).

Por vezes, Rogers (1980/1983) ficou insatisfeito pela concentração de atividades e responsabilidades em sua pessoa; no entanto, ele procurou em todos ser ele mesmo nessas diversas situações. 0 psicólogo humanista pondera, finalmente, que deixou uma marca no Brasil, em plena ditadura militar, ao expor suas ideias políticas relacionadas à democracia e à liberdade consciente. Além disso, ele considera que contribuiu de maneira essencial ao aprimoramento da Psicologia no Brasil. O autor destaca o fator que o fazia continuar se arriscando nessas empreitadas centradas na pessoa ao redor do mundo é que, fracassando ou obtendo sucesso, aprenderia com sua experiência e isso significaria envelhecer crescendo. 
Embora não faça menção direta à experiência de Rogers no Brasil, merece destaque o relato de Rachel Lea Rosenberg (1977) sobre o trabalho de implementação de uma comunidade centrada na pessoa. Desse capitulo, incluído no livro A pessoa como centro, é possível inferir que a autora se baseia em algumas experiências ocorridas nos EUA e no Brasil. O historiador da vida e obra de Rogers, Howard Kirschenbaum (2007), explicitamente faz uma menção às implicações políticas da ACP que Rogers apresentou ao público brasileiro sedento por democracia em um regime totalitário. Além do Brasil, Rogers e sua equipe estenderam suas experiências de facilitação grupal em outros países imersos em outros conflitos políticos, como a Irlanda do Norte e a África do Sul.

\section{Repercussões da visita de Carl Rogers ao Brasil}

Conforme foi exposto no tópico anterior, Rogers foi impactado pela sua vinda ao Brasil. Resta-nos perguntar: qual foi a repercussão dessa vinda ao público brasileiro? Uma primeira resposta possível seria a assunção de uma ACP neorogeriana (Frota, 2012). Esta, especificamente, não dá continuidade ao legado rogeriano, mas o atualiza conforme as discussões elaboradas pelos psicólogos brasileiros, dos quais muitos, atualmente reconhecidos no cenário nacional, participaram das visitas de Rogers ao Brasil. Contudo, algumas ideias desse autor foram recebidas de maneira crítica em razão de procederem de um contexto capitalista estadunidense. Nesse ponto, a ideia política de Rogers foi coloca à prova.

Conquanto as contribuições da ACP fossem bem-vindas e despertassem curiosidade, muitos pensadores influenciados por algumas teorias críticas aos mecanismos alienadores sociais questionaram e repensaram alguns aspectos da ACP. Situamos quatro exemplos que demarcam esse argumento.

O primeiro refere-se ao pensamento de Mauro Amatuzzi (1989), que, na obra O resgate da fala autêntica (1989), propõe um modelo relacional terapêutico e educacional norteado pelos aportes de Maurice Merleau-Ponty, Martin Buber, Paulo Freire e Carl Rogers. O resgate da autenticidade na relação é a finalidade proposta pelo autor que usa a ACP como o ponto de apoio para pensar o lugar da falaexpressão na experiência de ouvir o outro.

O segundo remete ao trabalho de Virginia Moreira $(1984,1990)$ que aponta os limites da ACP no que concerne ao seu trabalho educacional e de facilitação grupal. Inspirada pelos pensamentos marxista, freiriano, buberiano, nietzscheano e merleau-pontyano, a autora argumenta que a proposta rogeriana advém de um modelo homem individualista e capitalista, que ao se centrar na experiência alheia, não atinge plenamente as contendas sociais que a compõe. 
Em superação a isso, Moreira (2007) aponta uma teoria e prática clínica influenciada pelos pensamentos mencionados, sobretudo, a Fenomenologia de Merleau-Ponty.

O terceiro alude à proposta de facilitação grupal empregada por Afonso Fonseca (1988). Crítico as dimensões sociais alienantes que chegam ao indivíduo mediante o grupo, o autor recorre a Teoria Crítica, as sociologias de Michel Mafessoli e Karl Marx e as filosofias existenciais de Martin Buber e Friedrich Niestzche para pensar uma proposta crítica de grupo vivencial que gere experiências de relações mais integradas, conscientes e transformadoras do contexto social alienador.

O quarto acena para a retrospectiva crítica que José Célio Freire (1988) faz em relação ao pensamento de Rogers para questionar suas concepções de liberdade, responsabilidade, individualidade e as condições facilitadoras. Ao empregar Marx e Engels como lente crítica, o autor reconhece que Rogers tenta se aproximar de questões sociais e políticas mais amplas, porém de modo ingênuo, idealista e acrítico, favorecendo a expansão de um modelo de sociedade burguesa espelhada nos EUA.

Em comum, esses quatro exemplos apontam para uma recepção crítica das ideias de Rogers. Assim, a noção de política na ACP, embora reconhecida, é questionada e problematizada por autores diretamente imersos em um contexto de repressão política, ávidos por elaborar novas formas de relacionamento mais autêntico, consciente e situado aos problemas sociais do Brasil e aos mecanismos alienantes que atuam sobre a pessoa. Rogers em seu pensamento, por exemplo, não fez interface com o pensamento social com ideais marxistas durante a sua vinda ao Brasil, preocupou-se em transmitir que sua abordagem envolve um exercício de fomento à democracia. Resguardada a utilidade desse pensamento para ocasionar tal vinda, o público brasileiro escutou Rogers e não se prendeu a rogerianismos, desenvolvendo, deveras, outra ACP que não aquela do criador. Atualmente, essas críticas rumaram para o desenvolvimento de uma linhagem de ACP neorogeriana notoriamente caracterizada por influências fenomenológicas e existenciais (Frota, 2012).

Outra resposta à pergunta lançada, porém fora do campo tradicional da ACP e situada no âmbito maior da Psicologia Social, refere-se a obra de Cézar Wagner de Lima Góis (1994, 2003), para quem a obra de Rogers se apresenta como uma influência na constituição de um saber sobre Psicologia Comunitária, ao lado de figuras como Lev Vygotsky, Paulo Freire, Ignácio Martin-Baró e Rolando Toro. Esses pensadores, de acordo com Góis (1994), valorizam a dimensão de dialógica na constituição do humano e, a despeito de suas diferenças teóricas, podem ser pensados a partir de um elo ético, qual seja, a consideração do ser humano como um ser de potencialidades. 
Góis (2003) se inspira em Rogers para cunhar dois conceitos que apresenta como fundamentais em Psicologia Comunitária: valor pessoal, poder pessoal, bem como a ideia de núcleo de vida - muito próxima à de tendência à realização, como se verá a seguir. Valor Pessoal, para Góis (2003), é “( ...) um sentimento de valor intrínseco que se manifesta quando a pessoa entra em contato com o seu núcleo de vida, uma tendência natural para a realização" ( $p .51$ ). Assim, o valor pessoal se expressa no sentimento que a pessoa pode de ser capaz de influir na vida nos âmbitos individual e coletivo.

Já o poder pessoal, noção que atravessa toda a obra Sobre o poder pessoal (1977/2001), mas não é definida por Rogers em momento algum, é entendido por Góis (2003) como “( ...) a capacidade de influir em relações saudáveis com os outros e com a realidade. É a potência com que se vive a cada momento, buscando o crescimento de si e do outro e a transformação da realidade" (p. 51). O poder pessoal é um desdobramento concreto do valor pessoal, pois, à medida a pessoa se sente capaz de intervir no mundo, ela intensifica seu agir nessa direção.

Metodologicamente, Góis faz uso de uma curiosa junção do pensamento de Carl Rogers e Paulo Freire - junção essa desenvolvida, como já vimos, por Mauro Amatuzzi (1989), Virginia Moreira (1984, 2007), Afonso Fonseca (1988) e José Célio Freire (1988). Góis (1994) propõe o uso de círculos de encontro - uma mistura dos grupos de encontro propostos por Rogers (1970/2002) e os círculos de cultura propostos por Paulo Freire (1980). Trata-se de uma metodologia que trabalha questões vinculadas ao cotidiano de um grupo através de temas e palavras presentes na cultura de um espaço comunitário, num ambiente acolhedor, de reconhecimento de si e do outro, e que reconhece a imbricação entre as dinâmicas individual e coletiva. $O$ acolhimento do outro, tão bem trabalho por Rogers, se mistura ao aspecto político da palavra, tão enfatizado por Paulo Freire.

De acordo com Vieira e Ximenes (2011), a escolha de Rogers como base para uma Psicologia Comunitária feita por Góis se justifica na medida em que "(...) é ingenuidade crer que uma mudança social prescinda (sic) de mudanças pessoais, pois, caso os processos de mudança não façam sentido para os grupos envolvidos, eles não participam" (p. 307). Os mencionados autores, dessa forma, afirmam a importância da implicação de quem participa de atividades comunitárias na consecução de um ideal. Nesse sentido, os aludidos autores entendem que a inserção das ideias de Rogers no pensamento de Góis se justifica por um viés ético e o outro metodológico. O ponto de vista ético diria respeito à necessidade de consideração do outro como pessoa e, portanto, como digno de valor. Do ponto de vista metodológico, a dialogicidade presente nas proposições rogerianas servem de clara inspiração para um modelo 
de atuação que congrega afetos e racionalidade, ou ainda, política e implicação pessoal.

As ideias de Rogers, em suma, foram problematizadas, assimiladas e desenvolvidas pela Psicologia brasileira conforme algumas perspectivas clínicas, grupais e educacionais de ACP (Amatuzzi, 1989; Moreira, 1984, 1990, 2007; Freire, 1988; Fonseca, 1988) e segundo alguns elementos de influência da Psicologia Comunitária (Góis, 1994, 2003).

\section{Considerações finais}

A História da Psicologia no Brasil durante o período da Ditadura Militar contém variadas histórias a serem desveladas e/ou refletidas, através de pesquisas. Através de Carl Rogers, aprofundamos sua noção de política e como ela está imersa em sua abordagem exposta ao público brasileiro na ocasião de sua primeira visita ao país, em 1977. Após analisar alguns momentos da relação de Rogers com o cenário brasileiro, refletimos que ambos foram influenciados da seguinte forma: Rogers foi impactado pelo risco de apresentar seus ideais políticos a um contexto de psicólogos brasileiros imersos em uma Ditadura Militar; e os psicólogos brasileiros receberam as ideias e as práticas rogerianas com ressalvas e potencialidades para criar novas perspectivas teóricas e práticas de intervenção.

Em suma, das elaborações oriundas da visita de Rogers ao Brasil, apontamos que nos EUA, por um lado, Rogers acreditou que ele impactou o cenário político ditatorial brasileiro, que teve abertura para suas ideias políticas, após algumas articulações-explicações. No Brasil, por outro lado, constatamos que alguns psicólogos brasileiros apontaram os limites da ACP e os utilizaram como mote crítico, para desenvolver atualizações dessa abordagem no cenário nacional, e como inspiração, para desenvolver práticas comunitárias. Concluímos que a ACP brasileira, sobretudo na década de 1980, esteve imersa em uma série de conjeturas críticas sobre o lugar das ideias políticas de Rogers, passiveis de serem cooptadas e reconfiguradas, acriticamente, a partir de uma ótica capitalista voltada para a redemocratização do Brasil.

Apontamos, finalmente, a necessidade de aprofundar outras pesquisas sobre as visitas posteriores que Rogers fez ao Brasil, nos anos de 1978 e 1985, além de investigar como o serviço de Plantão Psicológico, uma prática de intervenção psicológica propriamente brasileira e com raízes na ACP, relacionou-se com o contexto ditatorial. 


\section{Referências}

Amatuzzi, M. (1989). O resgate da fala autêntica: filosofia da psicoterapia e da educação. Campinas, SP: Papirus.

Bandeira, E. (2012). Carl Rogers no Brasil. São Paulo: GRD Edições.

Brock, A. (2014). What is polycentric history of psychology?. Estudos e Pesquisas em Psicologia, 14(2), 646-659. Acesso em 19 de outubro de 2015, em http://www.epublicacoes.uerj.br/index.php/revispsi/article/view/12565

Dantas, A. (2014). A mídia e o golpe militar. Estudos Avançados, 28(80), 59-74.

Farber, D. \& Bailey, B. (2001). The Columbia guide to America in the 1960s. New York: Columbia University Press.

Fonseca, A. (1988). Grupo, fugacidade, ritmo e forma: processo de grupo e facilitação na psicologia humanista. São Paulo: Ágora.

Freire, J. (1988). Retrospectiva crítica da obra de Carl Roges: da 'terapia do relacionamento' à intuitividade dos 'momentos de movimento'. Revista de Psicologia, 6(1), 53-79.

Freire, P. (1980). Conscientização: teoria Teoria e prática da libertação: uma introdução ao pensamento de Paulo Freire. São Paulo: Corteza e Moraes.

Frota, A. (2012). Origens e destinos da abordagem centrada na pessoa no cenário brasileiro contemporâneo: reflexões preliminares. Revista da Abordagem Gestáltica, 18(2), 168-178.

Góis, C. (1994). Noções de Psicologia de Psicologia Comunitária. Fortaleza: Editora Viver.

Góis, C. (2003). Psicologia Comunitária no Ceará: uma caminhada. Fortaleza: Instituto Paulo Freire de Estudos Psicossociais.

Gomes, W., Holanda, A. \& Gauer, G. (2004). História das abordagens humanistas em psicologia no Brasil. In: M. Massimi (Org.). História da psicologia no Brasil do Século XX (pp. 105-129). São Paulo: E.P.U.

Grogan, J. (2012). Encountering America: humanistic psychology, sixties culture, and the shaping of the modern self. New York: Harper Collins.

Kirschenbaum, H. (2007). The life and work of Carl Rogers. Herefordshire: PCCS Books.

Moreira, V. (1984). Limites da Abordagem Centrada na Pessoa. Dissertação de Mestrado, Programa de Pós-Graduação em Educação, Universidade Federal do Ceará, Fortaleza, Brasil.

Moreira, V. (1990). Para além da pessoa: um estudo crítico da psicoterapia de Carl Rogers. Tese de Doutorado, Programa de Pós-Graduação em Psicologia, Pontifícia Universidade Católica de São Paulo, São Paulo, Brasil.

Moreira, V. (2007). De Carl Rogers a Merleau-Ponty: a pessoa mundana em psicoterapia. São Paulo: Annablume. 
Revista Veja. (1977). Entrevista Carl Rogers. Acessado em 03 de junho, 2015, em http://www.encontroacp. psc. br/site/entrevista-carl-rogers/

Rosenberg, R. (1977). Uma comunidade centrada na pessoa. In: C. Rogers \& R. Rosenberg. A pessoa como centro (pp. 103-132). São Paulo: EPU.

Rogers, C. (1977). Teoria e pesquisa. In: C. Rogers \& M. Kinget. Psicoterapia e relações humanas: teoria e prática da terapia não-diretiva (Vol. 1., pp. 143-274, M. Bizzotto, Trad.). Belo Horizonte: Interlivros (original publicado em 1959).

Rogers, C. (1983). Um jeito de ser (M. Kupfer, H. Lebrão \& Y. Patto, Trads.). São Paulo: EPU (original publicado em 1980).

Rogers, C. (1997). Tornar-se pessoa (M. Ferreira \& A. Lamparelli, Trads.). São Paulo: Martins Fontes (original publicado em 1961).

Rogers, C. (2001). Sobre o poder pessoal (W. Penteado, Trad.). São Paulo: Marins Fontes (original publicado em 1977).

Rogers, C. (2002). Grupos de encontro (J. Proença, Trad.). São Paulo: Martins Fontes (original publicado em 1970).

Rogers, C. \& Rosenberg, R. (1977). A pessoa como centro. EPU: São Paulo.

Rogers, C., Wood, J., O'Hara, M. \& Fonseca, A. (1983). Em busca de vida: da terapia centrada no cliente à abordagem centrada na pessoa. São Paulo: Summus.

Roszak, T. (1972). A contracultura: reflexões sobre a sociedade tecnocrática e a oposição juvenil. Petrópolis: Vozes (original publicado em 1968).

Santos, A. (2004). Momentos milagrosos: a natureza da força da mente nos relacionamentos e na psicoterapia. São Paulo: Vetor.

Santos, A., Rogers, C. \& Bowen, M. (1987). Quando fala o coração: a essência da psicoterapia centrada na pessoa. São Paulo: Vetor.

Tassinari, M. \& Portela, Y. (2002). História da abordagem centrada na pessoa no Brasil. In: S. Gobbi., S. Missel., H. Justo. \& A. Holanda (Orgs.). Vocabulários e noções básicas da abordagem centrada na pessoa (pp. 229-259). São Paulo: Vetor.

TV Cultura. (1977). Grupo de encontro no programa Panorama. Coleção Carl Rogers, $\mathrm{n}^{\circ}$ 7, DVD-R (80 min). Produzido por Tiago Cardoso, n.d.

Vieira, E. \& Ximenes, V. (2011). Reflexões sobre possíveis contribuições de Carl Rogers para a Psicologia Comunitária. In: A. Pimentel. \& V. Franco (Orgs.). Diálogos dentro da Psicologia: contributos da investigação luso-brasileira em psicologia social, clínica e educacional (pp. 301-310). Évora: Edições Aloendro. 


\section{Endereço para correspondência Ellen Araújo Lima Feitosa}

Universidade Federal da Bahia - UFBA

Rua Rio de Contas, 58, Candeias, CEP 45029-094, Vitória da Conquista - BA, Brasil Endereço eletrônico: ellenalf93@gmail.com

\section{Paulo Coelho Castelo Branco}

Universidade Federal da Bahia - UFBA

Rua Rio de Contas, 58, Candeias, CEP 45029-094, Vitória da Conquista - BA, Brasil

Endereço eletrônico: pauloccbranco@gmail.com

\section{Emanuel Meireles Vieira}

Universidade Federal do Pará - UFPA

Faculdade de Psicologia - Instituto de Filosofia e Ciências Humanas

Rua Augusto Correa, 1, Guamá, CEP 66073-040, Belém - PA, Brasil

Endereço eletrônico: emanuel.meireles@gmail.com

Recebido em: 17/02/2016

Reformulado em: 02/01/2017

Aceito em: 02/01/2017

\section{Notas}

* Psicóloga pela Universidade Federal do Bahia (UFBA). Especialista em Serviço Social em Saúde, Seguridades Social e Políticas Públicas (UNIGRAD).

** Psicólogo pela Universidade de Fortaleza (UNIFOR) e Mestre em Psicologia pela Universidade Federal do Ceará (UFC), Doutor em Psicologia pela Universidade Federal de Minas Gerais (UFMG) e professor adjunto da Universidade Federal do Bahia (UFBA).

*** Psicólogo e Mestre em Psicologia pela Universidade Federal do Ceará (UFC), Doutor em Psicologia pela Universidade Federal de Minas Gerais (UFMG) e professor adjunto da Universidade Federal do Pará (UFPA). À época da escrita do texto, bolsista Prodoutoral da Coordenação de Aperfeiçoamento de Pessoal da Nível Superior (CAPES). 